\title{
基于 ANSYS Workbench 的发动机连杆应力疲劳分析
}

\section{Stress Fatigue Analysis of Engine Connecting Rod Based on ANSYS Workbench}

\section{徐广晨 ${ }^{1}$ 李涛 $^{2}$ 张文武}

Guangchen $\mathrm{Xu}^{1} \quad{\mathrm{Tao} \mathrm{Li}^{2}}^{2}$ Wenwu Zhang ${ }^{1}$

\section{1.营口理工学院}

中国·辽宁 营口 115014;

2.营口信息技术学校

中国·辽宁 营口 115014

1.Yingkou Institute of Technology,

Yingkou, Liaoning, 115014, China;

2.Yingkou Information Technology School,

Yingkou, Liaoning, 115014, China

基金项目：营口理工学院 2018 应用型本

科建设自然科学项目【YBL201810】
【摘要】论文运用有限元分析技术, 建立了发动机连杆的三维有限元模型, 主要分析了 其在随机载荷下的应力疲劳。通过静力学分析结果, 确定连杆薄弱环节,得到了发动机连 杆在随机载荷下的应力、应变云图以及安全系数, 交替等效应力, 疲劳敏感度曲线图等, 为 发动机连杆的优化设计提供了数据参考。

【Abstract】In this paper, using the finite element analysis technique, a three-dimensional finite element model of the engine connecting rod is established, and the stress fatigue under random load is analyzed. Through the static analysis results, the weak link of the connecting rod is determined, and the stress, strain cloud and safety factor, alternating equivalent stress and fatigue sensitivity curve of the engine connecting rod under random load are obtained, which provides data reference for the optimal design of the engine connecting rod.

【关键词】发动机连杆; 随机载荷; 疲劳分析

【Keywords \engine connecting rod; random load; fatigue analysis

【DOI】10.36012/etr.v1i2.241

\section{1 引言}

连杆的作用是将横向运动转换为旋转运动。它是发动机 的一部分,它在负载下应该能保持足够的刚度,并且必须能够 传递轴向拉力、轴向压力。连杆通常设计为无限寿命, 但连杆 的损伤将导致发动机无法工作甚至报废。因此对连杆进行疲 劳分析, 可以有效防止连杆断裂事故的发生, 对提高发动机的 使用寿命和设计水平具有重要意义。

\section{2 连杆有限元模型}

为了获得准确的力学性能, 本文对连杆的一些非关键尺 寸进行了简化。借助 Solidworks 和 ANSYS Workbench 获得了 连杆的有限元模型, 采用六面体单元进行网格划分 ${ }^{[1-3]}$, 图 1 为连杆有限元模型, 其中有 12697 个单元, 26852 个节点。连 杆材料为 $40 \mathrm{Cr}$, 弹性模量为 $2.11 \times 10^{11} \mathrm{MPa}$, 泊松比为 0.31 , 用 于定义材料的 $\mathrm{S}-\mathrm{N}$ 曲线如图 2 所示 ${ }^{[1-3]}$ 。

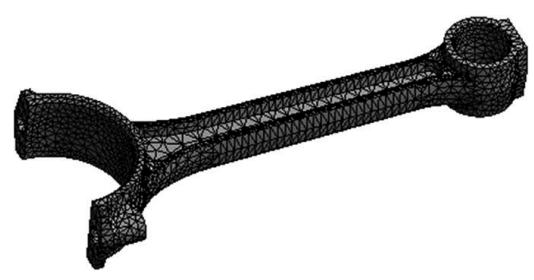

图 1 连杆有限元模型

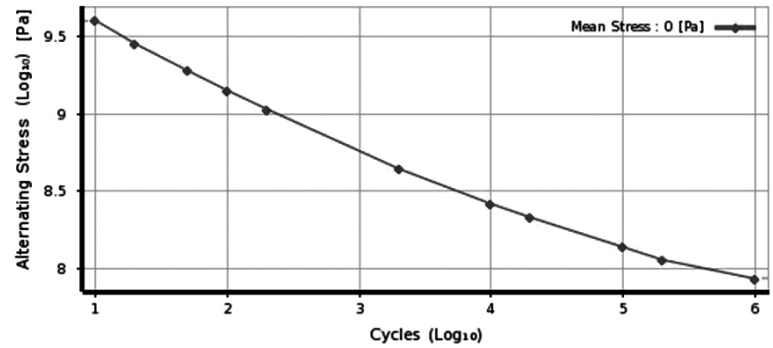

图 2 材料 S-N 曲线

\section{3 连杆随机载荷疲劳分析}

发动机连杆在工作时变换较为频繁, 且工作状态也较复 杂, 因此, 需要对连杆进行随机载荷状况下的疲劳强度分析。 进入 Workbench 下的 Fatigue Fool 模块, 设置疲劳强度系数为 0.85 , 施加随机疲劳载荷, 并将时程载荷数据放大 22 倍 ${ }^{[4]}$, 得 到随机载荷疲劳强度分析的结果如图 3 图 6 所示。

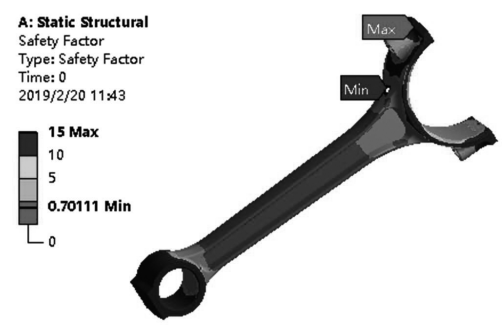

图 3 连杆安全系数云图 


\section{机械机电工程 Mechanical and Electrical Engineering}

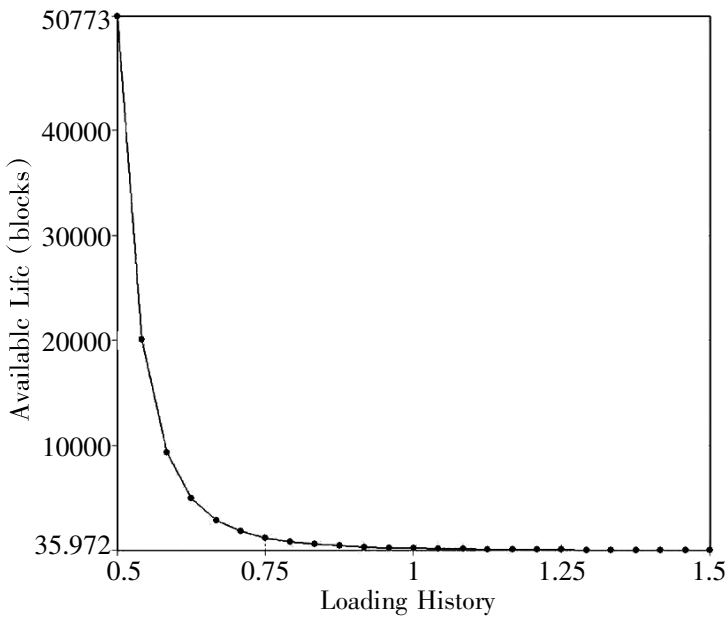

图 4 连杆疲劳敏感度曲线

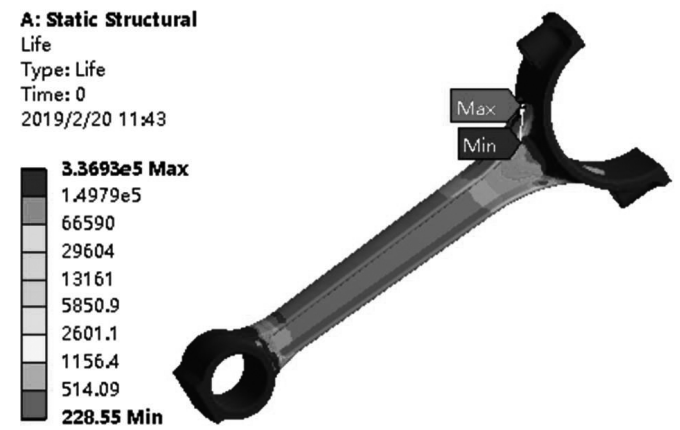

图 5 连杆寿命云图

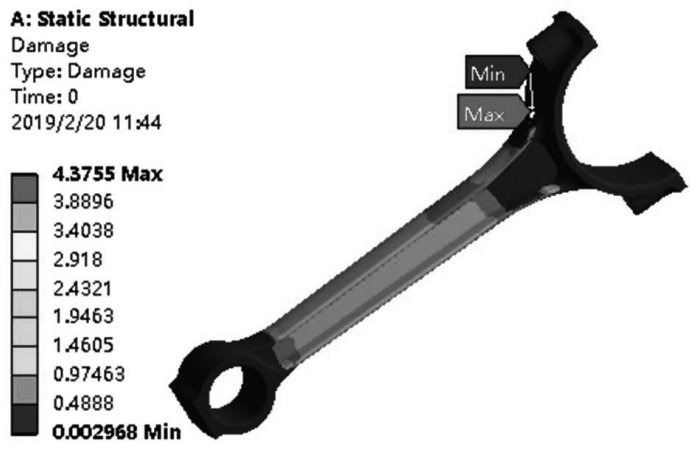

图 6 连杆损伤云图

通过雨流计数法, 得到雨流矩阵尺寸为 $30 \times 30$ 的分布直 方图如图 7 所示。雨流矩阵把实测载荷历程简化为若干个载 荷循环, 供疲劳寿命估算和编制疲劳试验载荷谱使用, $Z$ 轴表 示的是计数, 最大计数值为 87 。损伤矩阵能够提供实体评定 位置的损伤, $Z$ 轴表示的是相对损伤程度，最大损伤程度为 4.18 , 如图 8 所示 ${ }^{[-7]}$ 。

\section{4 结语}

本文基于 ANSYS Workbench 软件对发动机连杆在随机 载荷下的损伤情况进行了分析, 预测出了安全系数、疲劳寿命 及损伤,缩短了开发周期, 节约了开发成本, 为连杆的设计和
改进提供参考和依据。

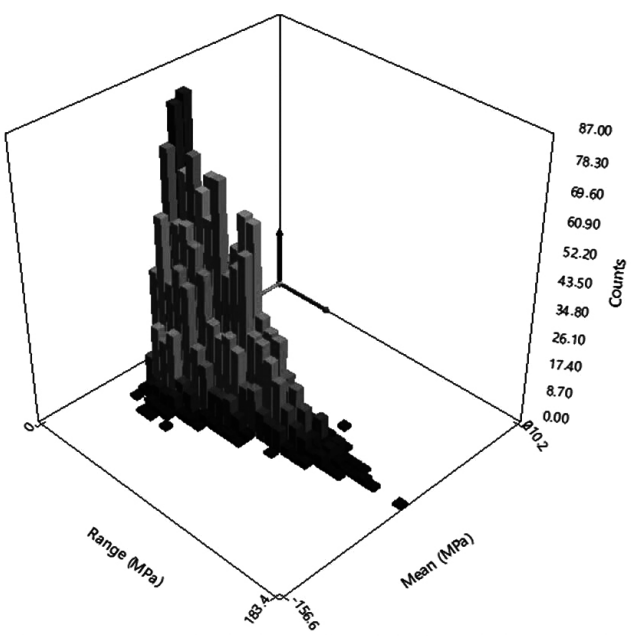

图 7 连杆雨流矩阵云图

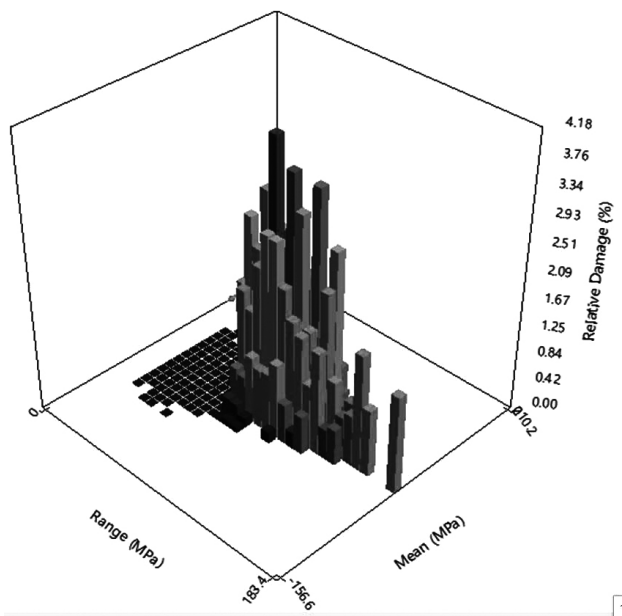

图 8 连杆疲劳损伤矩阵云图

\section{参考文献}

[1]张洪才,刘宪伟.ANSYS Workbench 14.5 数值模拟工程实例解 析[M].北京:机械工业出版社,2013.

[2]白帆,刘峰.发动机连杆在恒定振幅载荷下的应力疲劳分析 $[J]$. 机械制造与自动化,2017(1):124-125.

[3]朱荣福,赵卿峰.基于 ANSYS Workbench 的发动机连杆疲劳强 度分析[J].黑龙江工程学院学报,2014,4(28):31-33.

[4]王裕林,陈亮. 基于 AWE 的某型发动机连杆疲劳强度分析 [J]. 组合机床与自动化加工技术,2016(8):9-11.

[5]胡小华. 摩托车发动机连杆疲劳可靠性分析及寿命预测[D].重 庆:重庆交通大学,2014.

[6]山其新.汽车发动机连杆有限元分析与改进设计 [D].四川:电 子科技大学, 2017 .

[7]卢大平,祁文军.ANSYS 在连杆疲劳寿命分析中的应用 [J].汽 车零部件,2009(4):57-59. 